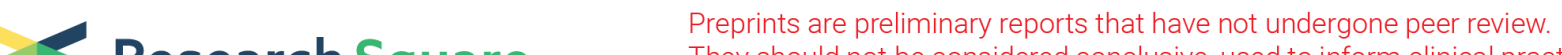 Research Square They should not be considered conclusive, used to inform clinical practice, or referenced by the media as validated information.
}

\section{Micropapillary pattern of pathologic IIIA-N2 lung adenocarcinoma is a prognostic factor after adjuvant chemoradiotherapy.}

Jian Zeng

Zhejiang Cancer Hospital

Xiaoying Cui

Zhejiang Cancer Hospital

Lei Cheng

Zhejiang Cancer Hospital

Ying Chen

Zhejiang Cancer Hospital

Xianghui Du

Zhejiang Cancer Hospital

liming sheng ( $\square$ m05shengliming@zju.edu.cn )

Zhejiang Cancer Hospital

\section{Research}

Keywords: Non-small cell lung cancer, Micropapillary pattern, Adjuvant chemoradiotherapy, Prognosis

Posted Date: June 4th, 2020

DOl: https://doi.org/10.21203/rs.3.rs-32920/v1

License: () (1) This work is licensed under a Creative Commons Attribution 4.0 International License.

Read Full License 


\section{Abstract}

Objectives: Lung adenocarcinoma with a micropapillary pattern is a highly aggressive disease and related to locoregional recurrence after surgery. This study aims to investigate the role of micropapillary pattern in pathologic IIIA-N2 lung adenocarcinoma after adjuvant chemoradiotherapy.

Methods: A total of consecutive 257 patients with pathologic IIIA-N2 lung adenocarcinoma who received adjuvant chemoradiotherapy were enrolled in this retrospective study. Patients were classified into three groups based on the proportion of micropapillary components: micropapillary negative (MPN), micropapillary minor component (MPM, positive but not predominant), and micropapillary predominant component (MPP, positive and predominant). The disease-free survival (DFS) and overall survival (OS) were analyzed using SPSS software.

Results: The five-year DFS and OS rates in the whole population were $41.0 \%$ and $62.7 \%$, respectively. MPP group had the shortest median DFS time and OS time, compared with the MPM group and the MPN group (Median DFS time: 27 months Vs. 39 months Vs. 62 months, $p=0.032$; Median OS time: 54 months Vs. 64 months Vs. not reached, $p=0.004)$. Furthermore, the micropapillary pattern was an independent prognostic factor for DFS and OS by multivariate analysis ( $\mathrm{p} \otimes 0.05)$.

Conclusion: Micropapillary pattern of pathologic IIIA-N2 lung adenocarcinoma was related to the earlier treatment failure and worse prognosis after adjuvant chemoradiotherapy.

\section{Introduction}

Surgically completely resected pathologic stage IIIA- $\mathrm{N}_{2}$ non-small cell lung cancer (NSCLC) is a very heterogeneous disease, with a 5 -year overall survival rate ranged from $14 \%$ to $51 \%$ [1-4]. Surgery and postoperative adjuvant chemotherapy are the cornerstone treatments. Even after such intensive treatment, $40 \%$ of patients still have a local-regional recurrence. A retrospective analysis of the ANITA study indicated that postoperative adjuvant radiotherapy (PORT) for pathologic IIIA- $\mathrm{N}_{2}$ patients could prolong survival time [5]. Furthermore, many retrospective studies showed that PORT is associated with an increase in survival in patients with $\mathrm{N}_{2}$ nodal disease [6, 7]. However, the role of adjuvant radiotherapy in this setting remains controversial before the results of large-scale randomized clinical trials. The currently ongoing randomized controlled trial LUNG ART ((NCT00410683) will give a clearer answer [8].

In 2011, invasive lung adenocarcinoma were classified as several subtypes based on the predominant pattern, including lepidic, acinar, papillary, solid, and micropapillary, as well as invasive mucinous adenocarcinoma according to the novel histologic IASLC/ATS/ERS classification [9]. The MPP subtype was found to be related to mediastinal lymph node metastasis and shorter disease-free survival time [10]. In early-stage NSCLC, patients with the MPP subtype were more prone to have a local-regional recurrence, with important implications for adjuvant radiotherapy and chemotherapy [11]. To our knowledge, whether lung adenocarcinoma subtypes are associated with tumor recurrence and prognosis remains unknown and needs further investigation. Therefore, we analyzed 257 consecutive patients who were diagnosed 
with completely resected pathologic stage IIIA-N 2 NSCLC between January 2013 and December 2017 in Cancer hospital of the University of Chinese Academy of Sciences (Zhejiang cancer hospital). This study aims to investigate the role of PORT in different histological subtypes of completely resected pathologic IIIA- $\mathrm{N}_{2}$ lung adenocarcinoma. We hope this result can bring new enlightenment to the beneficiaries of PORT in stage IIIA- $\mathrm{N}_{2}$ lung adenocarcinoma.

\section{Methods}

\section{Patients}

Between January 2013 and December 2017, patients with pathologic stage IIIA- $\mathrm{N}_{2}$ lung adenocarcinoma who received post-lobectomy adjuvant radiotherapy were enrolled in the study. Another inclusion criterion was that patients should undergo systematic thoracic lymph node dissection to ensure the accuracy of postoperative disease staging. Before surgery, patients underwent chest and abdomen computed tomography (CT), brain magnetic resonance imaging (MRI), and bone emission computed tomography (ECT) to exclude distant metastasis. A positron emission tomography-CT (PET-CT) scan was also recommended when it was possible. Pathologic staging for all patients was based on the AJCC $8^{\text {th }}$ TNM classification system. Patients who underwent palliative resection, segmentectomy, sleeve lobectomy, wedge resection, or total pneumonectomy were excluded from this study. Furthermore, patients who received neoadjuvant chemotherapy or diagnosed with previous or coexisting cancer other than lung adenocarcinoma were also excluded. Finally, a total of 257 eligible patients were enrolled in this retrospective study. This study was approved by the institutional review board of Cancer hospital of the University of Chinese Academy of Sciences (Zhejiang cancer hospital). Clinicopathological information such as age, gender, tumor location, histopathology, tumor stage, tumor diameter, resection margins, recurrence, and survival were obtained from patients' charts.

\section{Pathologic Evaluation}

Surgical specimens were routinely dehydrated, embedded in, and fixed according to the pathologic practice. Histopathological analysis of each slide was performed independently by two experienced pathologists. Lung adenocarcinoma was classified as six subtypes: lepidic, acinar, papillary, micropapillary, solid predominant subtypes, and invasive mucinous adenocarcinoma (IMA) according to the 2011 IASLC/ATS/ERS lung adenocarcinoma classification system [9]. For the specimen mixed by more than two subtypes, the histological subtype was defined as the predominant subtype, which occupied the highest percentage. According to the proportion of micropapillary subtype, histopathological subtypes were divided into three groups: MPP (Micropapillary predominant component), MPM (Micropapillary minor component), MPN (Micropapillary negative).

\section{Adjuvant chemotherapy and radiotherapy}


All patients underwent postoperative adjuvant chemotherapy with pemetrexed plus cisplatin. Intramuscular injection of vitamin B12 and folic acid were administered one week before pemetrexed chemotherapy. Pemetrexed was intravenously administered at a dose level of $500 \mathrm{mg} / \mathrm{m}^{2}$ day 1 , and cisplatin was administered at a dose of $25 \mathrm{mg} / \mathrm{m}^{2}$ day $1-3$, every 21 days for four cycles. If the patient had serious chemotherapy complications at the prescribed dose, the dose of chemotherapy drugs could be reduced by $20 \%$. Chemotherapy could be suspended if intolerable side effects occur or if the patient refused to continue chemotherapy.

Sequential radiotherapy initiated after the completion of adjuvant chemotherapy. PORT was delivered by intensity-modulated radiotherapy (IMRT), which was designed by Philips Radiation Oncology Systems (Pinnacle version 8.0). The clinical target volume (CTV) included the bronchial stump, involved mediastinal nodal stations, and corresponding high-risk draining lymph node stations, which were defined by Femke et al [12]. The plan target volume (PTV) was defined as the CTV plus 5-15 mm to account for the daily setup variation and respiratory movement. The radiotherapy was administered in $2.0 \mathrm{~Gy}$ once daily for five days per week up to a total dose of $50 \mathrm{~Gy}$. The dose limitations of the surrounding organs at risk were as followings: the lung mean dose was of below $16.0 \mathrm{~Gy}, \mathrm{~V}_{20}$ (volume receiving above $20 \mathrm{~Gy}$ ) $<30 \%, \mathrm{~V}_{30}$ (volume receiving above $30 \mathrm{~Gy}$ ) $<20 \%$ and $\mathrm{V}_{5}$ (volume receiving above $5 \mathrm{~Gy})<60 \%$, respectively. The $\mathrm{V}_{40}$ of the heart was below $40 \%$. The maximum spinal cord dose was 45.0 Gy. The PTV encompassed at least a 95\% isodose line. The dose-volume histogram (DVH) was obtained for PTV, spinal cord, lung, and heart.

\section{Statistical analysis}

A Pearson's chi-square test was used to assess the correlation between lung adenocarcinoma subtypes and clinicopathological variables, such as gender, age, tumor location, tumor diameter, and T stage. Disease-free and overall survival was analyzed by Cox proportional hazards regression and KaplanMeier curves. Furthermore, we used the Cox proportional hazards model with the backward selection method for multivariate analysis. The factor analyzed in univariate analysis $(p<0.05)$ was included in the multivariate analysis. All statistical calculations were performed with SPSS 13.0 for Windows (Chicago, IL, USA). A p-value of less than 0.05 was considered statistically significant.

\section{Results}

\section{Patients' characteristics}

A total of consecutive 257 patients were enrolled in this retrospective study. The characteristics of these patients are summarized in Table 1. There were $127(49.4 \%)$ men and $130(50.6 \%)$ women. Patients' age ranged from 25 to 78 years (median: 58 years). According to the AJCC $8^{\text {th }}$ TNM staging system, 103 patients (40.1\%) were $\mathrm{T}_{1}, 126(49.0 \%) \mathrm{T}_{2}$, and $28(10.9 \%) \mathrm{T}_{3}$. The lesions were located in 99 cases of left lung and 158 cases of the right lung. Tumor diameter ranged from $0.9 \mathrm{~cm}$ to $11.0 \mathrm{~cm}$, with a median 
diameter of $2.5 \mathrm{~cm}$. A total of 4353 lymph nodes were removed after pathological examination, and the number of positive lymph nodes was 1380 . The number of positive mediastinal lymph nodes were distributed from one to 26 . A total of 124 patients were found to have driver gene alteration, 106 with epidermal growth factor receptor (EGFR) mutation, and 18 with anaplastic lymphoma kinase (ALK) gene rearrangement. Of the 257 patients, 22 had a lung adenocarcinoma containing a micropapillarypredominant, 34 papillary-predominant, 32 solid-predominant, 38 lepitic-predominant, 89 acinarpredominant, and 42 invasive mucinous lung adenocarcinoma.

\section{The relationship between clinicopathological variables and histological patterns}

The relationship between clinicopathological variables and histological patterns in lung adenocarcinoma patients is presented in Table 1. According to the proportion of micropapillary subtype, 22 patients were classified as MPP, 78 MPM, and 157 MPN. There was no association between the histological patterns and patients' age $(p=0.770)$. Compared with male patients, female patients had more MPP or MPM, but the difference was not statistically significant $(p=0.098)$. Lung adenocarcinoma with MPP or MPM had a larger mass, more advanced stage, and more mediastinal lymph node metastasis, but there was no statistical difference ( $\mathrm{p} \otimes 0.05)$. The histological pattern was related to driver gene alteration and pleural invasion ( $\mathrm{p} \otimes 0.05)$. MPP or MPN was significantly higher in patients with positive pleural invasion ( $p=$ $0.011)$ and patients with positive EGFR mutation or ALK gene rearrangement $(p=0.006)$.

\section{Survival analysis}

The median follow-up time was 40.0 months (range: 5-94 months). Tumor recurrence was observed in 129 patients $(50.2 \%)$ of all patients. sixty-seven patients $(26.1 \%)$ died due to disease progression. The 5 year disease-free survival and overall survival rates were $41.0 \%$ and $62.7 \%$, respectively. The median disease-free survival and overall survival time were 46.0 months and 83.0 months, respectively.

The 5-year DFS and OS rates for the different histological patterns, respectively, were $20.5 \%$ and $39.5 \%$ for MPP, $24.5 \%$ and $55.1 \%$ for MPM, and $53.6 \%$ and $72.2 \%$ for MPN (Figure 1 for DFS and Figure 2 for OS). Patients with MPP showed significantly shorter DFS time compared with the other two groups (The median DFS time: 27.0 months for MPP Vs. 39.0 months for MPM Vs. 62.0 months for MPN, $p=0.032$ ).

Furthermore, histological patterns were divided into two groups (Micropapillary present and micropapillary absent) based on the presence of micropapillary components. Univariate analysis indicated that micropapillary $(H R=1.56, p=0.012)$, tumor diameter $(H R=1.57, p=0.013), T$ stage $(H R=$ $2.02, p=0.037)$ and the total number of positive lymph nodes $(H R=1.42, p=0.049)$ were significantly associated with DFS (Shown in Table 2). These prognostic variables were incorporated into the multivariate analysis. The results indicated that micropapillary, tumor diameter and T stage were three independent prognostic factors for DFS. The prognostic variables identified in the univariate analysis of 
OS, including micropapillary $(H R=2.13, p=0.002)$, the total number of positive lymph nodes $(H R=1.68$, $p=0.033)$ and pleural invasion ( $H R=1.69, p=0.034)$, all remained significant in the multivariate analysis. Patients with micropapillary present had an elevated risk of disease progression and death compared to those with micropapillary absent. The hazard ratio was 1.58 (95\% confidence interval [Cl] 1.08-2.30) for disease progression and $1.85(95 \% \mathrm{Cl} 1.09-3.12)$ for death.

\section{Discussion}

The aim of this study was to investigate the relationship between the classification of subtyping lung adenocarcinoma and prognosis in patients with pIIIA- $\mathrm{N}_{2}$ lung adenocarcinoma. This study included a relatively large sample of 257 patients with lung adenocarcinoma. The histological pattern was related to driver gene alteration, pleural invasion, and prognosis. Multivariate analysis showed that component of micropapillary was associated with worse patient outcomes.

Stage pIIIA-N2 lung adenocarcinoma is a group of very heterogeneous diseases. For resectable patients, surgical treatment is the standard treatment. Although there is a potential for cure, $60 \%$ of patients are still prone to relapse and metastasis after treatment, resulting in death [13]. Therefore, the treatment of patients with stage plll- $\mathrm{N}_{2}$ lung adenocarcinoma should be multidisciplinary treatment, including surgery, chemotherapy, and radiotherapy. However, the most reasonable treatment options and layout are still in the exploration stage. The role of PORT for patients with stage pIIIA- $\mathrm{N}_{2}$ NSCLC remains controversial. In 1998 , an individualized meta-analysis based on nine randomized controlled clinical trials showed that the use of PORT is detrimental to unselected NSCLC populations [14]. Study results have shown that PORT harms patient survival, directly increasing the risk of death by 1.21 times. Subgroup analysis suggested that PORT reduced the survival of $\mathrm{N}_{0-1}$ patients. However, for patients with $\mathrm{N}_{2}$ disease, the use of PORT did not jeopardize survival but also does not benefit survival. After the meta-analysis was published, the usage rate of PORT gradually decreased until the ANITA trial results were announced [15]. In 2008, the ANITA trial explored the difference between postoperative chemotherapy and placebo in operative NSCLC and analyzed the effect of PORT on patient survival time [5]. The results of the study found that $\mathrm{pN}_{2}$ patients treated with postoperative chemotherapy combined with sequential PORT could obtain a longer median survival time (47.4 months Vs. 23.8 months) and a higher 5-year survival rate (47.4\% Vs. 34.0\%) than postoperative chemotherapy alone. After this, many large retrospective studies based on the SEER database or NCDB database showed that PORT could greatly reduce the risk of death in patients with IIIA $\mathrm{N}_{2}$ resectable NSCLC $[7,16]$. A small sample prospective randomized controlled study published in 2014 compared the effect of postoperative adjuvant chemoradiotherapy (POCRT) and postoperative adjuvant chemotherapy (POCT) in patients with pIIIA $N_{2}$ [17]. Patients in the POCRT group received PORT (50.4 Gy/28 fractions) concurrently with two cycles of chemotherapy followed by another two cycles of consolidative chemotherapy. A total of 135 patients were enrolled in this study. Compared with the POCT group, the median DFS time of the POCRT group was significantly prolonged (28 months Vs. 18 months). However, due to the small sample size, there is no difference in OS between the two groups. A phase III randomized controlled study called "LUNG ART" exploring the role of PORT in stage IIIA-N ${ }_{2}$ NSCLC is 
underway [18]. In this study, all patients with pIIIA- $\mathrm{N}_{2}$ underwent postoperative adjuvant chemoradiation. The total dose of PORT was $50 \mathrm{~Gy}$. The 5-year disease-free survival and overall survival rates of the entire group of patients were $41.0 \%$ and $62.7 \%$, respectively. This result is better than historical data $[7,19,20]$. The main reason is that half of the patients found to have a positive driver gene. After the treatment failed, they took corresponding targeted therapy, which greatly prolonged the survival time. The second reason is because of the use of PORT, which has greatly improved the local and regional control rates of these patients.

Many previous studies have explored the prognostic factors of stage pIIIA $\mathrm{N}_{2}$ NSCLC, including primary tumor size [21], lymph node ratio [22], number of lymph node stations [23], and mediastinal lymph node size [24]. In this study, tumor size was an independent prognostic factor. Our findings are consistent with a previous study based on a relatively small sample size [21]. Chen et al. [21] retrospectively analyzed 77 consecutive patients with stage pIIIA- $\mathrm{N}_{2}$ NSCLC and found that tumor size $<3 \mathrm{~cm}$ was associated with a better prognosis. The second finding in our study was that component of micropapillary was found to relate to driver gene alteration and pleural invasion. Furthermore, MPP was associated with worse patient outcomes. Cai et al. [25] analyzed the data of 261 lung adenocarcinoma to investigate the relationship between intratumoral heterogeneity and treatment response. EGFR sensitive mutation occurred more frequently in papillary, lepidic, and micropapillary components. It is suggesting that EGFR-TKI should be limited to patients with micropapillary or papillary lung adenocarcinoma. Similarly, Tsuta et al. [26] found that EGFR mutations, KRAS gene mutations, and ALK gene alterations were statistically prevalent in micropapillary-predominant lung adenocarcinomas $(p=0.00001)$. The component of micropapillary has even changed some treatment indications. In a large retrospective study [27], stage IB NSCLC patients with micropapillary components could benefit from postoperative adjuvant chemotherapy. The usage of chemotherapy in patients with MPP pattern reduced lung cancer-specific death by $54 \%$. The component of micropapillary in EGFR-mutant NSCLC was related to the earlier brain metastasis indicated that it is necessary to conduct rigorous follow-up examinations of the central nervous system for these patients in order to detect brain metastases at an early time and seek better control. Leeman et al [11] treated stage IIIA lung adenocarcinoma with stereotactic body radiation therapy (SBRT). One hundred and nineteen patients were enrolled. $30 \%$ of pateints who diagnosed with solid and/or micropapillary pattern lung adenocarcinoma were defined as high risk subtype. The presence of a micropapillary component predicts an increased risk of tumor recurrence. It is suggested that it is necessary to elevate the total radiation dose or adjuvant systemic or targeted therapy for early stage lung adenocarcinoma patients who received SBRT.

Our study is limited by its retrospective nature and selective biases. Furthermore, information on posttreatment recurrence was insufficient, which might vary the survival of patients. A prospective study is required to determine the prognostic value of histological subtype. Besides, the study lacks a control group that does not do the PORT, so it is impossible to draw a conclusion about which histological subtype can benefit from PORT. 


\section{Conclusions}

In summary, we evaluated the association of lung adenocarcinoma histologic patterns with prognosis. The component of micropapillary was associated with worse outcomes. These findings may help identify patients with stage pIIIA- $\mathrm{N}_{2}$ NSCLC eligible to PORT.

\section{Abbreviations}

NSCLC: Non-small cell carcinoma; MPN: micropapillary negative; MPM: micropapillary minor component; MPP: micropapillary predominant component; DFS: disease-free survival; OS: overall survival; PORT: postoperative adjuvant radiotherapy; $\mathrm{CT}$ : computed tomography; MRI: magnetic resonance imaging; ECT: emission computed tomography; PET-CT: positron emission tomography-CT; IMA: invasive mucinous adenocarcinoma; IMRT: intensity-modulated radiotherapy; CTV: clinical target volume; PTV: plan target volume; DVH: dose-volume histogram; EGFR: epidermal growth factor receptor; ALK:anaplastic lymphoma kinase.

\section{Declarations}

\section{Ethics approval and consent to participate}

This study was approved by the Zhejiang Cancer hospital Institutional Review Board.

\section{Availability of data and material}

All data generated or analysed during this study are included in this published article.

\section{Acknowledgements}

We thank all the patients who participated in this study and their families.

\section{Consent for publication}

Not applicable

\section{Competing interests}

The authors declare that they have no competing interests.

\section{Authors' contributions}


JZ, LMS: Data collection and analysis and the drafting of the manuscript. XYC: Analysis and interpretation of the data. LC: Conception and study design. XHD: Drafting of the manuscript. All authors read and approved the final manuscript.

\section{Funding}

This study was supported by grants from the Nature Science Foundation of Zhejiang Province (no LY14H160012).

\section{Author details}

1. Department of Thoracic Surgery, Cancer hospital of the University of Chinese Academy of Sciences (Zhejiang cancer hospital), Hangzhou, Zhejiang, China

2. Institute of Cancer and Basic Medicine $\mathrm{IBMC} \triangle$, Chinese Academy of Sciences, Hangzhou, Zhejiang, China

3. Department of Radiotherapy, Cancer hospital of the University of Chinese Academy of Sciences (Zhejiang cancer hospital), Hangzhou, Zhejiang, China

4. Key Laboratory Diagnosis and Treatment Technology on Thoracic Oncology, Zhejiang, China

5. The Second Clinical Medical College, Zhejiang Chinese Medical University.

\section{References}

1.Van Schil P, Van Meerbeeck J, Kramer G, Splinter T, Legrand C, Giaccone G, et al. Morbidity and mortality in the surgery arm of EORTC 08941 trial. The European respiratory journal. 2005; 26: 192-7.

2.van Meerbeeck JP, Kramer GW, Van Schil PE, Legrand C, Smit EF, Schramel F, et al. Randomized controlled trial of resection versus radiotherapy after induction chemotherapy in stage IIIA-N2 non-smallcell lung cancer. Journal of the National Cancer Institute. 2007; 99: 442-50.

3.Eberhardt WE, Pottgen C, Gauler TC, Friedel G, Veit S, Heinrich V, et al. Phase III Study of Surgery Versus Definitive Concurrent Chemoradiotherapy Boost in Patients With Resectable Stage IIIA(N2) and Selected IIIB Non-Small-Cell Lung Cancer After Induction Chemotherapy and Concurrent Chemoradiotherapy (ESPATUE). Journal of clinical oncology: official journal of the American Society of Clinical Oncology. 2015; 33: 4194-201.

4.Rajaram R, Correa AM, Xu T, Nguyen QN, Antonoff MB, Rice D, et al. Locoregional Control, Overall Survival, and Disease-Free Survival in Stage IIIA (N2) Non-Small-Cell Lung Cancer: Analysis of Resected and Unresected Patients. Clinical lung cancer. 2020. 
5.Douillard JY, Rosell R, De Lena M, Riggi M, Hurteloup P, Mahe MA, et al. Impact of postoperative radiation therapy on survival in patients with complete resection and stage I, II, or IIIA non-small-cell lung cancer treated with adjuvant chemotherapy: the adjuvant Navelbine International Trialist Association (ANITA) Randomized Trial. International journal of radiation oncology, biology, physics. 2008; 72: 695701.

6.Lally BE, Zelterman D, Colasanto JM, Haffty BG, Detterbeck FC, Wilson LD. Postoperative radiotherapy for stage II or III non-small-cell lung cancer using the surveillance, epidemiology, and end results database. Journal of clinical oncology: official journal of the American Society of Clinical Oncology. 2006; 24: 2998-3006.

7.Robinson CG, Patel AP, Bradley JD, DeWees T, Waqar SN, Morgensztern D, et al. Postoperative radiotherapy for pathologic N2 non-small-cell lung cancer treated with adjuvant chemotherapy: a review of the National Cancer Data Base. Journal of clinical oncology: official journal of the American Society of Clinical Oncology. 2015; 33: 870-6.

8.Le Pechoux C, Dunant A, Faivre-Finn C, Thomas PA, Pourel N, Lerouge D, et al. Postoperative Radiotherapy for Pathologic N2 Non-Small-Cell Lung Cancer Treated With Adjuvant Chemotherapy: Need for Randomized Evidence. Journal of clinical oncology: official journal of the American Society of Clinical Oncology. 2015; 33: 2930-1.

9.Travis WD, Brambilla E, Noguchi M, Nicholson AG, Geisinger KR, Yatabe Y, et al. International association for the study of lung cancer/american thoracic society/european respiratory society international multidisciplinary classification of lung adenocarcinoma. Journal of thoracic oncology: official publication of the International Association for the Study of Lung Cancer. 2011; 6: 244-85.

10.Warth A, Muley T, Meister M, Stenzinger A, Thomas M, Schirmacher P, et al. The novel histologic International Association for the Study of Lung Cancer/American Thoracic Society/European Respiratory Society classification system of lung adenocarcinoma is a stage-independent predictor of survival. Journal of clinical oncology: official journal of the American Society of Clinical Oncology. 2012; 30: 1438-46.

11.Leeman JE, Rimner A, Montecalvo J, Hsu M, Zhang Z, von Reibnitz D, et al. Histologic Subtype in Core Lung Biopsies of Early-Stage Lung Adenocarcinoma is a Prognostic Factor for Treatment Response and Failure Patterns After Stereotactic Body Radiation Therapy. International journal of radiation oncology, biology, physics. 2017; 97: 138-45.

12.Spoelstra FO, Senan S, Le Pechoux C, Ishikura S, Casas F, Ball D, et al. Variations in target volume definition for postoperative radiotherapy in stage III non-small-cell lung cancer: analysis of an international contouring study. International journal of radiation oncology, biology, physics. 2010; 76: 1106-13. 
13.Goldstraw P, Crowley J, Chansky K, Giroux DJ, Groome PA, Rami-Porta R, et al. The IASLC Lung Cancer Staging Project: proposals for the revision of the TNM stage groupings in the forthcoming (seventh) edition of the TNM Classification of malignant tumours. Journal of thoracic oncology: official publication of the International Association for the Study of Lung Cancer. 2007; 2: 706-14.

14.Postoperative radiotherapy in non-small-cell lung cancer: systematic review and meta-analysis of individual patient data from nine randomised controlled trials. PORT Meta-analysis Trialists Group. Lancet. 1998; 352: 257-63.

15.Douillard JY, Rosell R, De Lena M, Carpagnano F, Ramlau R, Gonzales-Larriba JL, et al. Adjuvant vinorelbine plus cisplatin versus observation in patients with completely resected stage IB-IIIA non-smallcell lung cancer (Adjuvant Navelbine International Trialist Association [ANITA]): a randomised controlled trial. The Lancet Oncology. 2006; 7: 719-27.

16.Wei S, Xie M, Tian J, Song X, Wu B, Liu L. Propensity score-matching analysis of postoperative radiotherapy for stage IIIA-N2 non-small cell lung cancer using the Surveillance, Epidemiology, and End Results database. Radiation oncology. 2017; 12: 96.

17.Shen WY, Ji J, Zuo YS, Pu J, Xu YM, Zong CD, et al. Comparison of efficacy for postoperative chemotherapy and concurrent radiochemotherapy in patients with IIIA-pN2 non-small cell lung cancer: an early closed randomized controlled trial. Radiotherapy and oncology: journal of the European Society for Therapeutic Radiology and Oncology. 2014; 110: 120-5.

18.Le Pechoux C. Role of postoperative radiotherapy in resected non-small cell lung cancer: a reassessment based on new data. The oncologist. 2011; 16: 672-81.

19.Asamura H, Chansky K, Crowley J, Goldstraw P, Rusch VW, Vansteenkiste JF, et al. The International Association for the Study of Lung Cancer Lung Cancer Staging Project: Proposals for the Revision of the N Descriptors in the Forthcoming 8th Edition of the TNM Classification for Lung Cancer. Journal of thoracic oncology: official publication of the International Association for the Study of Lung Cancer. 2015; 10: 1675-84.

20.Groome PA, Bolejack V, Crowley JJ, Kennedy C, Krasnik M, Sobin LH, et al. The IASLC Lung Cancer Staging Project: validation of the proposals for revision of the $\mathrm{T}, \mathrm{N}$, and $\mathrm{M}$ descriptors and consequent stage groupings in the forthcoming (seventh) edition of the TNM classification of malignant tumours. Journal of thoracic oncology: official publication of the International Association for the Study of Lung Cancer. 2007; 2: 694-705.

21.Chen CY, Wu BR, Chen CH, Cheng WC, Chen WC, Liao WC, et al. Prognostic Value of Tumor Size in Resected Stage IIIA-N2 Non-Small-Cell Lung Cancer. Journal of clinical medicine. 2020; 9.

22. Han H, Zhao Y, Gao Z, Zheng D, Fu F, Zhao Z, et al. A prognostic score system with lymph node ratio in stage IIIA-N2 NSCLC patients after surgery and adjuvant chemotherapy. Journal of cancer research and 
clinical oncology. 2019; 145: 2115-22.

23.Yoon HY, Lee JC, Kim SW, Kim HR, Kim YH, Choi SH, et al. Prognosis of multi-level N2-positive nonsmall cell lung cancer according to lymph node staging using endobronchial ultrasound-transbronchial biopsy. Thoracic cancer. 2018; 9: 684-92.

24.Rice SR, Molitoris JK, Vyfhuis MAL, Edelman MJ, Burrows WM, Feliciano J, et al. Lymph Node Size Predicts for Asymptomatic Brain Metastases in Patients With Non-small-cell Lung Cancer at Diagnosis. Clinical lung cancer. 2019; 20: e107-e14.

25.Cai Y, Wu H, Shi X, Dong Y, Chang X, Zhang L, et al. Heterogeneous components of lung adenocarcinomas confer distinct EGFR mutation and PD-L1 expression. BMC cancer. 2020; 20: 148.

26.Tsuta K, Kawago M, Inoue E, Yoshida A, Takahashi F, Sakurai H, et al. The utility of the proposed IASLC/ATS/ERS lung adenocarcinoma subtypes for disease prognosis and correlation of driver gene alterations. Lung cancer. 2013; 81: 371-6.

27.Qian F, Yang W, Wang R, Xu J, Wang S, Zhang Y, et al. Prognostic significance and adjuvant chemotherapy survival benefits of a solid or micropapillary pattern in patients with resected stage IB lung adenocarcinoma. The Journal of thoracic and cardiovascular surgery. 2018; 155: 1227-35 e2.

\section{Tables}

Table 1 The relationship between clinicopathological variables and histological pattern in lung adenocarcinoma patients 


\begin{tabular}{|c|c|c|c|c|c|}
\hline Variables & $\mathrm{n}$ & MPP & $\overline{\mathrm{MPM}}$ & MPN & $\mathrm{p}$ \\
\hline $\begin{array}{l}\text { Female } \\
\text { Male }\end{array}$ & $\begin{array}{l}130 \\
127\end{array}$ & $\begin{array}{l}13(10.0) \\
9(7.1)\end{array}$ & $\begin{array}{l}46(35.4) \\
32(25.2)\end{array}$ & $\begin{array}{l}71(54.6) \\
86(67.7)\end{array}$ & 0.098 \\
\hline $\begin{array}{r}\geq 60 \\
\square 60\end{array}$ & $\begin{array}{l}155 \\
102\end{array}$ & $\begin{array}{l}12(7.7) \\
10(9.8)\end{array}$ & $\begin{array}{l}49(31.6) \\
29(28.4)\end{array}$ & $\begin{array}{l}94(60.6) \\
63(61.8)\end{array}$ & 0.770 \\
\hline $\begin{array}{r}\text { Tumor location } \\
\text { Left } \\
\text { Right }\end{array}$ & $\begin{array}{c}99 \\
158\end{array}$ & $\begin{array}{c}10(10.1) \\
12(7.6)\end{array}$ & $\begin{array}{l}33(33.3) \\
45(28.5)\end{array}$ & $\begin{array}{c}56(56.6) \\
101(63.9)\end{array}$ & 0.482 \\
\hline $\begin{array}{l}\text { Tumor diameter } \\
\leq 3 \mathrm{~cm} \\
\square 3 \mathrm{~cm}\end{array}$ & $\begin{array}{c}176 \\
81\end{array}$ & $\begin{array}{l}13(7.4) \\
9(11.1)\end{array}$ & $\begin{array}{l}52(29.5) \\
26(32.1)\end{array}$ & $\begin{array}{c}111(63.1) \\
46(56.8)\end{array}$ & 0.503 \\
\hline $\begin{array}{c}\mathrm{T}_{1} \\
\mathrm{~T}_{2-3}\end{array}$ & $\begin{array}{l}103 \\
154\end{array}$ & $\begin{array}{c}7(6.8) \\
15(9.7)\end{array}$ & $\begin{array}{l}24(23.3) \\
54(35.1)\end{array}$ & $\begin{array}{l}72(69.9) \\
85(55.2)\end{array}$ & 0.060 \\
\hline $\begin{array}{c}\text { Total number of positive LN } \\
\leq 44 \\
05\end{array}$ & $\begin{array}{l}147 \\
110\end{array}$ & $\begin{array}{l}10(6.8) \\
12(10.9)\end{array}$ & $\begin{array}{l}44(29.9) \\
34(30.9)\end{array}$ & $\begin{array}{l}93(63.3) \\
64(58.2)\end{array}$ & 0.466 \\
\hline $\begin{array}{l}\text { Total number of positive MLN } \\
\qquad \leq 2\end{array}$ & $\begin{array}{c}174 \\
83\end{array}$ & $\begin{array}{l}13(7.5) \\
9(10.8)\end{array}$ & $\begin{array}{l}48(27.6) \\
30(36.1)\end{array}$ & $\begin{array}{c}113(64.9) \\
44(53.0)\end{array}$ & 0.182 \\
\hline $\begin{array}{c}\text { Station status of MLN } \\
\text { Single } \\
\text { Multiple }\end{array}$ & $\begin{array}{c}161 \\
96\end{array}$ & $\begin{array}{l}13(8.1) \\
9(9.4)\end{array}$ & $\begin{array}{l}42(26.1) \\
36(37.5)\end{array}$ & $\begin{array}{l}106(65.8) \\
51(53.1)\end{array}$ & 0.117 \\
\hline $\begin{array}{c}\text { Driver gene alteration } \\
\text { Negative } \\
\text { Positive }\end{array}$ & $\begin{array}{l}133 \\
124\end{array}$ & $\begin{array}{l}11(8.3) \\
11(8.9)\end{array}$ & $\begin{array}{l}29(21.8) \\
49(39.5)\end{array}$ & $\begin{array}{l}93(69.9) \\
64(51.6)\end{array}$ & 0.006 \\
\hline $\begin{array}{l}\text { Pleural invasion } \\
\text { Negative } \\
\text { Positive }\end{array}$ & $\begin{array}{l}143 \\
114\end{array}$ & $\begin{array}{c}9(6.3) \\
13(11.4)\end{array}$ & $\begin{array}{l}35(24.5) \\
43(37.7)\end{array}$ & $\begin{array}{l}99(69.2) \\
58(50.9)\end{array}$ & 0.011 \\
\hline $\begin{array}{c}\text { Lymphovascular Invasion } \\
\text { Negative } \\
\text { Positive }\end{array}$ & $\begin{array}{c}191 \\
66\end{array}$ & $\begin{array}{l}14(7.3) \\
8(12.1)\end{array}$ & $\begin{array}{l}55(28.8) \\
23(34.8)\end{array}$ & $\begin{array}{c}122(63.9) \\
35(53.0)\end{array}$ & 0.240 \\
\hline $\begin{array}{r}\text { Nerve invasion } \\
\text { Negative } \\
\text { Positive }\end{array}$ & $\begin{array}{c}234 \\
23 \\
\end{array}$ & $\begin{array}{c}22(9.4) \\
0(0)\end{array}$ & $\begin{array}{c}72(30.8) \\
6(26.1) \\
\end{array}$ & $\begin{array}{c}140(59.8) \\
17(73.9) \\
\end{array}$ & 0.224 \\
\hline
\end{tabular}

MPP, Micropapillary predominant; MPM, Micropapillary minor; MPN, Micropapillary negative; LN, Lymph node; MLN, Mediastinal lymph nodes

Table 2 Univariable and multivariable analyses of disease-free survival and overall survival using Cox's regression 


\begin{tabular}{|c|c|c|c|c|c|c|}
\hline \multirow{2}{*}{ Variables } & \multicolumn{3}{|c|}{ Univariate analysis } & \multicolumn{3}{|c|}{ Multivariate analysis } \\
\hline & $\mathrm{HR}$ & $95 \% \mathrm{CI}$ & $\mathrm{p}$ & $\mathrm{HR}$ & $95 \% \mathrm{CI}$ & $\mathrm{p}$ \\
\hline $\begin{array}{l}\text { ee survival } \\
0 \text { Vs } \square 60 \text { ) }\end{array}$ & 1.17 & $0.83-$ & 0.372 & & & \\
\hline (Male Vs Female) & 0.96 & $0.68-$ & 0.792 & & & \\
\hline pillary (Present Vs absent) & 1.56 & $1.10-$ & 0.012 & 1.58 & $1.08-$ & 0.019 \\
\hline xcation (Right Vs Left) & 0.72 & $0.51-$ & 0.063 & & & \\
\hline iameter $(\square 3 \mathrm{~cm}$ Vs $\leq 3 \mathrm{~cm})$ & 1.57 & $\begin{array}{l}1.10- \\
2.25\end{array}$ & 0.013 & 2.14 & $\begin{array}{l}1.30- \\
3.54\end{array}$ & 0.003 \\
\hline$\left(\mathrm{T}_{2-3} \mathrm{Vs} \mathrm{T}_{1}\right)$ & 2.02 & $\begin{array}{l}1.04- \\
3.89\end{array}$ & 0.037 & 1.99 & $1.02-$ & 0.043 \\
\hline mber of positive LN ( $\mathrm{a} 5 \mathrm{Vs} \leq 4$ ) & 1.42 & $\begin{array}{l}1.00- \\
2.00\end{array}$ & 0.049 & & & \\
\hline mber of positive MLN ( $\square 3$ Vs $\leq 2$ ) & 1.05 & $0.73-$ & 0.808 & & & \\
\hline number of MLN (Multiple Vs Single) & 1.24 & $\begin{array}{l}0.87- \\
1.77\end{array}$ & 0.225 & & & \\
\hline nvasion (Positive Vs Negative) & 1.17 & $0.73-$ & 0.354 & & & \\
\hline $\begin{array}{l}\text { vascular Invasion (Positive Vs } \\
\text { a) }\end{array}$ & 1.13 & $0.76-$ & 0.536 & & & \\
\hline ıvasion (Positive Vs Negative) & 0.95 & $\begin{array}{l}0.51- \\
1.77\end{array}$ & 0.882 & & & \\
\hline $\begin{array}{l}\text { Irvival } \\
0 \text { Vs } \square 60)\end{array}$ & 0.88 & $\begin{array}{l}0.54- \\
1.42\end{array}$ & 0.592 & & & \\
\hline (Male Vs Female) & 1.30 & $\begin{array}{l}0.80- \\
2.10\end{array}$ & 0.290 & & & \\
\hline pillary (Present Vs absent) & 2.13 & $\begin{array}{l}1.31- \\
3.46\end{array}$ & 0.002 & 1.85 & $\begin{array}{l}1.09- \\
3.12\end{array}$ & 0.022 \\
\hline xcation (Right Vs Left) & 1.18 & $\begin{array}{l}0.71- \\
1.97\end{array}$ & 0.514 & & & \\
\hline iameter $(\square 3 \mathrm{~cm}$ Vs $\leq 3 \mathrm{~cm})$ & 1.21 & $\begin{array}{l}0.74- \\
2.00\end{array}$ & 0.447 & & & \\
\hline$\left(\mathrm{T}_{2-3} \mathrm{Vs}_{1}\right)$ & 1.68 & $\begin{array}{l}1.04- \\
2.72\end{array}$ & 0.033 & 1.79 & $\begin{array}{l}1.08- \\
2.98\end{array}$ & 0.025 \\
\hline mber of positive LN ( $\square 5 \mathrm{Vs} \leq 4$ ) & 1.24 & $\begin{array}{l}0.76- \\
2.00\end{array}$ & 0.393 & & & \\
\hline mber of positive MLN ( $\square 3$ Vs $\leq 2$ ) & 1.42 & $\begin{array}{l}0.84- \\
2.38\end{array}$ & 0.186 & & & \\
\hline number of MLN (Multiple Vs Single) & 1.33 & $\begin{array}{l}0.82- \\
2.15\end{array}$ & 0.255 & & & \\
\hline nvasion (Positive Vs Negative) & 1.69 & $\begin{array}{l}1.04- \\
2.74\end{array}$ & 0.034 & 2.55 & $\begin{array}{l}1.13- \\
5.79\end{array}$ & 0.025 \\
\hline $\begin{array}{l}\text { vascular Invasion (Positive Vs } \\
\text { ə) }\end{array}$ & 1.65 & $\begin{array}{l}1.00- \\
2.74\end{array}$ & 0.053 & & & \\
\hline ıvasion (Positive Vs Negative) & 1.07 & $\begin{array}{l}0.46- \\
2.48 \\
\end{array}$ & 0.873 & & & \\
\hline
\end{tabular}

Figures 


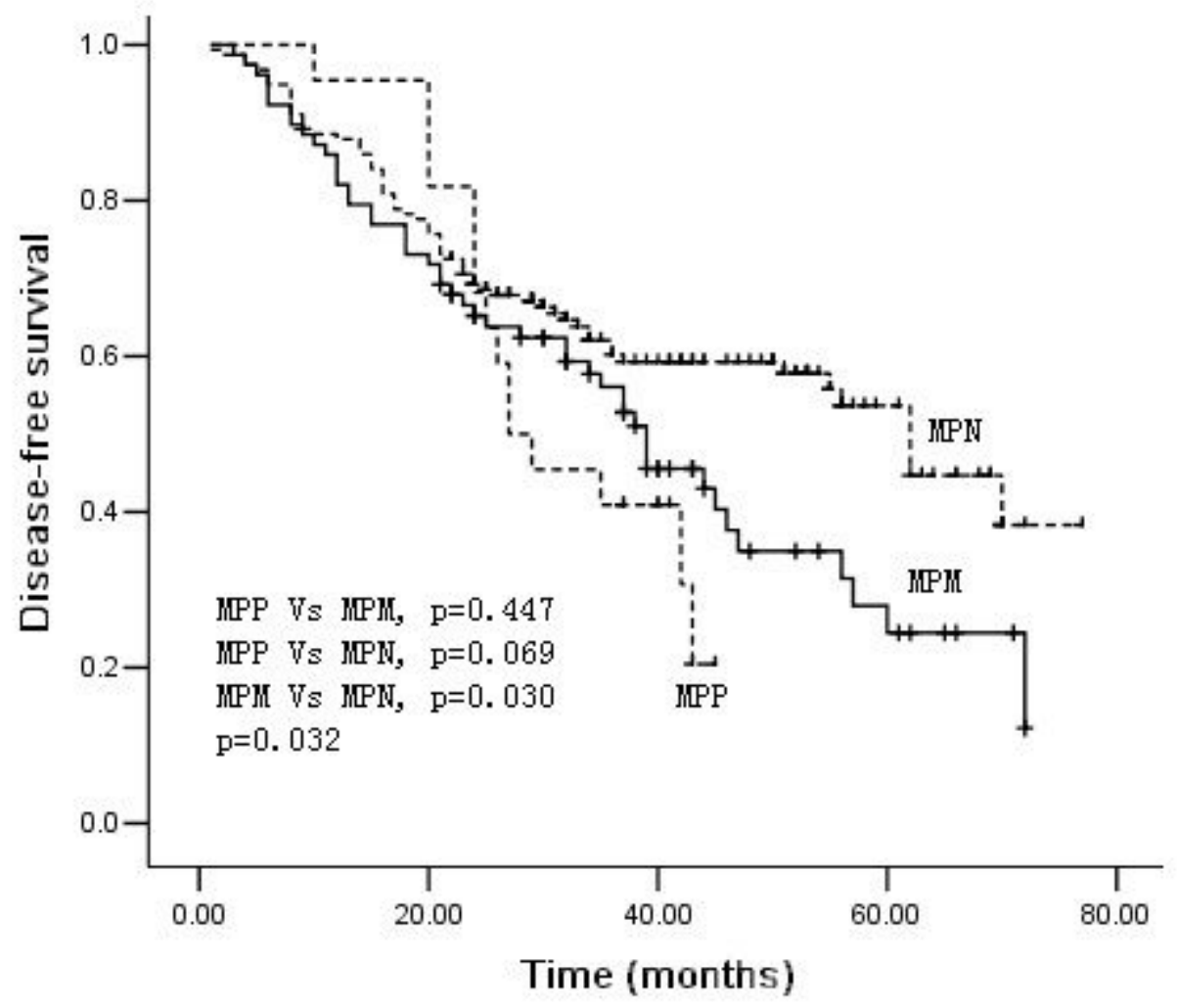

\section{Figure 1}

Kaplan-Meier survival curves of disease-free survival for different histological patterns. MPP, Micropapillary predominant; MPN, Micropapillary minor; MPN, Micropapillary negative. 


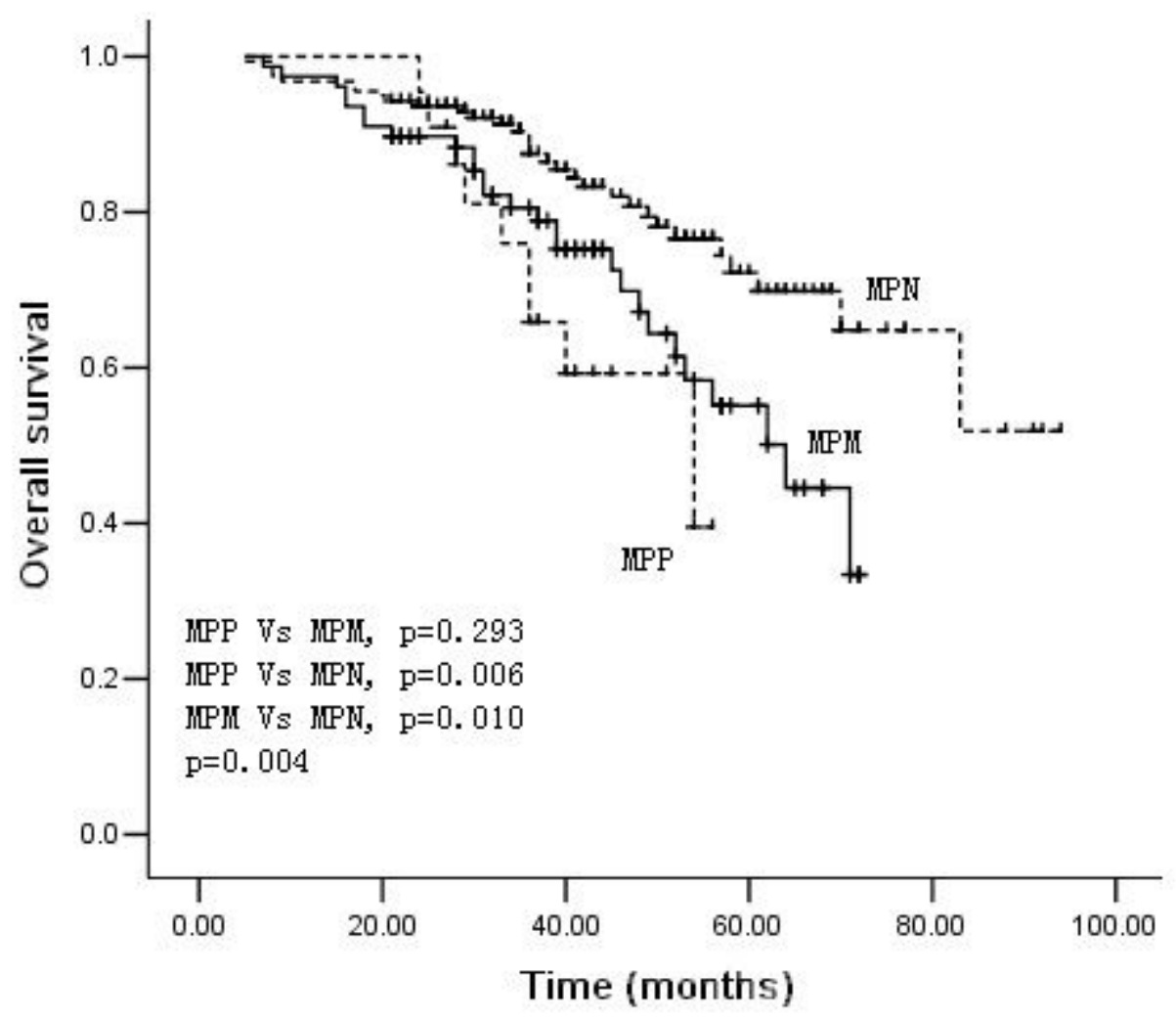

Figure 2

Kaplan-Meier survival curves of overall survival for different histological patterns. MPP, Micropapillary predominant; MPN, Micropapillary minor; MPN, Micropapillary negative. 